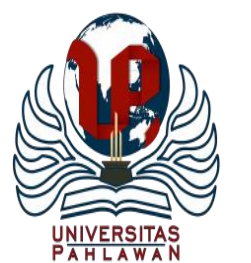

Edukatif : Jurnal Ilmu Pendidikan Volume 3 Nomor 5 Tahun 2021 Halm 2380 - 2391

EDUKATIF: JURNAL ILMU PENDIDIKAN

Research \& Learning in Education

https://edukatif.org/index.php/edukatif/index

\title{
Pengembangan Media M-Learning Berbasis Aplikasi Articulate Storyline untuk Meningkatkan Hasil Belajar Peserta Didik Sekolah Menengah Atas
}

\author{
Ana Dwi Octavia ${ }^{1 凶}$, Jun Surjanti², Bambang Suratman ${ }^{3}$ \\ Universitas Negeri Surabaya, Indonesia ${ }^{1,2,3}$ \\ E-mail : ana.19003@mhs.unesa.ac.id ${ }^{1}$, junsurjanti@unesa.ac.id ${ }^{2}, \underline{\text { bambangsuratman42@gmail.com }}^{3}$
}

\begin{abstract}
Abstrak
Penelitian di latarbelakangi dengan adanya pandemic COVID-19 dan pentingnya penguasaan teknologi bagi pendidik dalam menyampaikan materi pembelajaran yang diwujudkan dengan adanya media pembelajaran. Tujuan penelitian ini yaitu untuk mengembangkan media M-learning berbasis Articulate Storyline untuk meningkatkan hasil belajar peserta didik. Penelitian ini merupakan penelitian pengembangan dengan melibatkan ahli materi, ahli media dan ahli bahasa. Model pengembangan yang digunakan yaitu Thiagarajan yang terdiri dari 4 tahapan yaitu Define, Design, Development dan Diseminasi. Untuk mengukur keberhasilan hasil belajar peserta didik maka menggunakan Uji Test dengan sebelumnya menggunakan uji hipotesis yaitu uji homogenitas dan uji normalitas. Hasil penelitian menyatakan bahwa media M-learning berbasis Articulate Storyline untuk meningkatkan hasil belajar peserta didik bersifat valid, praktis dan signifikan
\end{abstract}

Kata Kunci: media pembelajaran m-learning berbasis articulate storyline, Hasil Belajar

\begin{abstract}
The research was motivated by the COVID-19 pandemic and the importance of mastering technology for educators in delivering learning materials that were realized by the existence of learning media. The purpose of this study is to develop an Articulate Storyline-based M-learning media to improve student learning outcomes. This research is development research involving material experts, media experts, and linguists. The development model used is Thiagarajan which consists of 4 stages, namely Define, Design, Development, and Dissemination. To measure the success of student learning outcomes, use the Test Test by previously using the hypothesis test, namely the homogeneity test and the normality test. The results of the study stated that the Articulate Storyline-based M-learning media to improve student learning outcomes was valid, practical, and significant.
\end{abstract}

Keywords: articulate storyline-based m-learning learning media, learning outcomes

Copyright (c) 2021 Ana Dwi Octavia, Jun Surjanti, Bambang Suratman

$\triangle$ Corresponding author:

Email : ana.19003@mhs.unesa.ac.id

DOI $:$ https://doi.org/10.31004/edukatif.v3i5.797

ISSN 2656-8063 (Media Cetak)

ISSN 2656-8071 (Media Online)

Edukatif : Jurnal Ilmu Pendidikan Vol 3 No 5 Tahun 2021 p-ISSN 2656-8063 e-ISSN 2656-8071 
2381 Pengembangan Media M-Learning Berbasis Aplikasi Articulate Storyline untuk Meningkatkan Hasil Belajar Peserta Didik Sekolah Menengah Atas - Ana Dwi Octavia, Jun Surjanti, Bambang Suratman DOI: https://doi.org/10.31004/edukatif.v3i5.797

\section{PENDAHULUAN}

Pandemi Covid 19 memberi dampak yang luar biasa pada semua bidang. Salah satunya bidang pendidikan. Dengan mewabahnyanya covid 19 menjadikan pembelajaran menjadi pembelajaran jarak jauh dengan menerapkan sistem daring. Dalam system pembelajaran daring menjadikan tantangan bagi guru untuk tetap meningkatkan hasil pembelajaran peserta didik meningkat yang melebihi KKM Kriteria Ketuntasan Minimal (Yunitasari \& Hanifah, 2020) . Berbagai permasalahan ditemukan selama pembelajaran secara daring antara lain turunnya motivasi pembelajaran, terbatasanya kuota internet, kurangnya kerja sama antara orang tua dan peserta didik sehingga tujuan pembelajaran banyak yang belum tercapai (Nafrin \& Hudaidah, 2021). Pentingnya penguasaan teknologi bagi guru dalam mengelola pembelajaran agar pembelajaran bisa berjalan efektif dan mencapai tujuan pembelajaran khususnya pada pada masa pandemic seperti ini. Berdasarkan observasi di beberapa sekolah ditemukan bahwa media pembelajaran yang digunakan di beberapa sekolah menengah atas masih berupa PPT , media social dan pembelajaran secara konvensional saja yang digunakan dalam pembelajaran. Sehingga dalam semester awal masih banyak ditemukan penurunan hasil belajar peserta didik di semua sekolah menengah atas. Permasalahan lain dari peserta didik dalam pembelajaran yaitu masalah keuangan peserta didik yang tidak sanggup jika mereka mengeluarkan banyak uang untuk pembelajaran daring.

Pemecahan permasalahan tersebut yaitu dengan memperbaiki proses pembelajaran salah satunya dengan pengembangan media pembelajaran yang sejalan dengan perkembangan teknologi, sehingga pada akhirnya akan meningkatkan kualitas pendidikan di Indonesia. Pendidikan merupakan suatu usaha secara sadar merubah perilaku manusia ke arah yang lebih baik mengikuti perubahan yang terjadi di masyarakat dan perkembangan zaman sehingga menjadikan manusia yang bergun bagi bangsa dan Negara (Suriadi et al., 2021). Pendidikan itu akan dapat tercapai salah satunya dengan adanya peran guru yang professional dalam mengembangakan media pembelajaran .Hal tersebut juga diperjelas dengan adanya undang-undang guru dan dosen no 14 tahun 2005 yang berisi bahwa seorang guru merupakan seorang pendidik yang handal yang tugas utamanya adalah mendidik, melatih, membimbing dan mengevaluasi peserta didik pada pembelajaran anak usia dini, sekolah dasar, sekolah menengah dan sekolah tinggi. Pada undang undang tersebut sudah jelas bahwa seorang guru haruslah meningkatkan pengetahuannya dalam mengajar agar materi yang disampaikan dapat terserap dengan baik kepada peserta didik. Salah satu komponen penting dalam pendidikan yang menentukan kualitas pendidikan adalah pendidik dan peserta didik disamping kurikum dan fasilitas pendidikan (Effendi \& Hendriyani, 2018). Tinggi rendahnya mutu pendidikan sangat ditentukan oleh kualitas pendidik dan peserta didik, maka dari itu seorang guru harus meningkatkan kemampuan profesionalnya yang kita kenal dengan CPD, (Continous Profesional Development). Perception and Practices Continous Profesional Development merupakan landasan profesionalisme serta mutu guru untuk memenuhi kebutuhan peserta didik yang terus berubah sehingga akan meningkatkan hasil belajar peserta didik (Asmari, 2016). Mobile learning merupakan salah satu alternative media pembelajaran bagi guru dalam mengembangakan profesi keberlanjutan (Effendi \& Hendriyani, 2018)

Faktor yang berperan penting dalam proses pembelajaran salah satunya adalah media pembelajaran. Kemajuan teknologi membuat dampak yang signiikan terhadap kemajuan media pembelajaran yang merupakan alat penunjang bagi pembelajaran yang merupakan alat komukasi yang efektif bagi tercapainyan tujuan pembelajaran (Pranaja \& Astuti, 2019). Diharapkan dengan media pembelajaran juga mampu merangsang pemikiran peserta didik perhatian dan minat sehingga mampu memahami pembelajaran dengan baik (Dasar, 2016). Selain itu media merupakan salah satu faktor yang berperan penting bagi guru dalam menyampaikan materi pembelajaran agar materi pembelajaran dipahami peserta didik dengan baik (Wahyuningtyas \& Sulasmono, 2020). Sehingga baik itu pendidik maupun peserta didik haruslah mengikuti perkembangan media pembelajaran sejalan dengan perkembangan teknologi. Media pembelajaran yang 
digunakan dalam proses pembelajaran juga diharapkan tidak akan membebani peserta didik terutama dalam masalah keuangan. Maka media yang tepat digunakan pada pembelajaran yaitu media M-Learning.

Dengan adanya media pembelajaran juga diharapkan akan membantu peserta didik dalam pencapaian hasil belajar yang yang memuaskan tanpa adanya kecemasan akan ketertinggalan materi pembelajaran terutama pada masa pandemic covid 19 ini yang membatasi kegiatan pembelajaran secara tatap muka.

Media pembelajaran yang saat ini praktis digunakan adalah media M-Learning . M-Learning merupakan media pembelajaran yang menggunakan teknologi portable tanpa mengenal ruang dan waktu dengan potensi keunggulannya menjadi suatu media yang dapat meningkatkan efisiensi dan efektifitas pembelajaran bagi manusia khususnya peserta didik (Martono Kurniawan \& Nurhayati Oky, 2014). Kelebihan M-Learning yaitu sebagai penguat bagi peserta didik yang mengikuti pembelajaran konvensional dan sebagai alternative media pembelajaran sehingga peserta didik dapat mengatur agenda pembelajaran sehari-hari dengan fleksibel (Novaliendry et al., 2020).Media M-Learning juga akan lebih menarik jika dikembangkan menggunakan sebuah aplikasi Articulate Storyline. Oleh sebab itu tujuan penelitian ini yaitu bagaimana pengembangan media pembelajaran M-Learning berbasis aplikasi Articulate Storyline dalam meningkatkan hasil belajar peserta didik pada uji terbatas peserta didik kelas X di sekolah Menengah ke atas.

Penelitian ini didukung oleh beberapa penelitian terdahulu yang telah mengembangkan media pembelajaran media pembelajaran Articulate Storyline. Media pembelajaran Articulate Storyline memperoleh validasi yang baik dari 4 validator sehingga dapat disimpulkan bahwa media pembelajaran menggunakan Articulate Storyline sangat layak digunakan dalam proses pembelajaran (Purnama \& Asto B, 2014). Penelitian lain juga menunjukkan bahwa pemanfaatan M-Learning berpengaruh positif signifikan terhadap efektivitas perilaku belajar organisasi.(Surjanti et al., 2018) Selain itu penelitian lain menemukan bahwa pembelajaran menggunakan M-Learning akan mengurangi tingkat kecemasan peserta didik dalam mempelajari materi yang sulit sehingga mereka akan dapat lebih muda materi yang diajarkan oleh guru (Alioon \& Delialioğlu, 2019) dengan menggunakan media pembelajaran Articulate Storyline capaian belajar peserta didik bisa mencapa rata-rata 75 dan media pembelajaran articulate Storyline ini mendapatkan skor validitas sangat baik dari ahli media (Pratama, 2019). Media pembelajaran Articulate Storyline ini juga bisa diaplikasikan kedalam media apapun seperti tablet, laptop, computer dan smartphone. (Hadza et al., 2020) menjelaskan bahwa aplikasi Articulate Storyline ini bisa diakses menggunakan internet karena media ini bias berbentuk HTML 5 dan juga bisa diakses menggunakan laptop dan smartphone. Program tersebut juga memudahkan pengguna untuk publish secara online maupun offline sehingga dapat diformat dalam bentuk $\mathrm{CD}$, word processing, laman personal dan LMS yang dikenal dengan smart brainware.

Dengan adanya media M-learning berbasis Articulate Storyline ini diharapkan akan membantu peserta didik dalam menghadapi kesulitan belajar. Disini peranan guru harus mempu menyelesaikan kesulitan belajar yang menghambat proses pembelajaran sehingga belum tercapainya tujuan pembelajaran dengan memberikan penanganan khusus pada peserta didik yang mengalami kesulitan belajar (Munirah, 2018). Penilaian hasil belajar dikatakan tuntas apabila hasil belajar memenuhi penilaian yang disesuaikan Kriteria Ketuntasan Minimal (KKM) yang telah diatur oleh satuan pendidikan itu sendiri. KKM ditentukan oleh satuan pendidikan mengacu pada Standar Kompetensi Lulusan (SKL) dengan mempertimbangkan karakteristik peserta didik, karakteristik mata pelajaran, dan kondisi satuan Pendidikan dapat dilihat dari aspek pengetahuan, sikap, dan ketrampilan (Dasar, 2016). Hasil belajar merupakan suatu acuan untuk menentukan ukuran kemampuan dan kompetensi yang dimilik peserta didik setelah memperoleh pengalaman belajar (Destyana \& Surjanti, 2021). Tujuan dari penilai hasil belajar ini yaitu untuk mengetahui kemajuan pembelajaran sehingga bisa mengadakan koreksi dalam kegiatan pembelajaran. Hal ini sesuai dengan pernyataan bahwa penilaian hasil belajar sendiri bertujuan untuk mengevaluasi proses kemajuan belajar dan perbaikan pembelajaran secara berkesinambungan. (Juandi, 2019). Hasil Belajar yang dimaksud dalam penelitian ini adalah kemampuan yang 
dicapai peserta didik dalam bidang kognitif yang dinyatakan dalam bentuk angka-angka atau skor dari hasil tes setelah proses pembelajaran melalui media pembelajaran M-Learning berbasis aplikasi Articulate Storyline

Berdasarkan beberapa hasil peneltian sebelumnya disimpulkan bahwa penggunaan media pembelajaran $M$-Learning dapat meningkatkan hasil belajar peserta didik hal tersebut dikarenakan penggunaan media $M$ learning dapat mengurangi kecemasan peserta didik akan materi yang sulit untuk dipelajari tanpa adanya kekhawatiran akan ketinggalam materi walaupun pembelajaran dilakukan secara daring. Begitu juga dengan adanya media Articulate Storyline yang mendapatkan skor validitas sangat baik dari ahli media sehingga terdapat peningkatan capaian belajar peserta didik. Pada kenyataannya yang penulis temui bahwa tidak semua media $M$-Learning dapat meningkatkan hasil belajar peserta didik apabila tampilan dalam media $M$-Learning tidak menarik . M-learning yang digunakan cenderung masih bersifat media social seperti WA dimana fokusnya tidak sepenuhnya digunakan dalam pembelajaran. Maka dari itu dalam penelitian ini akan mengembangakan media $M$-Learning yang lebih menarik

Penulis ingin mendalami lebih lanjut dari hasil hasil penelitian sebelumnya yang menunjukan bahwa peranan media M-learning sangat penting dalam pembelajaran. Selain media M-Learning penggunaan media Articulate Storyline dirasa sangat menarik dengan banyak ahli media yang memberikan skor sangat baik dalam penilaian media ini sehingga dapat tercapainya hasil belajar peserta didik. Berdasarkan hal tersebut maka penulis ingin mengembangkan media M-learning ini menggunakan Articulate Storyline yang dirasa masih jarang pengembangan media M-learning berbasis Articulate Storyline dalam pembelajaran. Maka fokus peneltian ini yaitu pengembangan media pembelajaran M-Learning berbasis Articulate Storyline dapat meningkatkan hasil belajar peserta didik pada sekolah menengah atas mengingat bahwa penelitian penelitian sebelumnya belum mengkaji secara mendalam penggunaan media M-Learning apabila dikembangkan dengan aplikasi Articulate Storyline. Disini dapat dilihat perbedaan dan keunikan penelitian sekarang dibandingkan dengan penelitian sebelumnya.

\section{METODE PENELITIAN}

Penelitian ini merupakan penelitian pengembangan dengan menggunakan model Thiagarajan mengacu pada Four-D-Model. Four-D-Model merupakan pengembangan instruksional yang membagi menjadi empat tahapan yaitu Define, Design, Development, dan Dessiminate. Pada tahap pendefinisian ini yaitu dengan observasi awal, analisis kebutuhan peserta didik, analisis tugas, analisis konsep dan analisis tujuan pembelajaran. Pada tahap perancangan dengan cara penyusunan kriteria tes awal peserta didik, pemilihan media pembelajaran, penentuan desain isi materi pembelajaran kemudian dilanjut dengan perancangan awal penyusunan skenario pembelajaran pada media pembelajaran. Kemudian yang ke tiga yaitu tahapan pengembangan media pembelajaran M-Learning Berbasis Articulate Storyline dengan sebelumnya divalidasi oleh ahli materi, ahli media dan ahli bahasa. Setelah divalidasi dan mendapatakan kritikan peneliti merevisi media pembelajaran M-Learning berbasis Articulate Storyline. Kemudian media pembelajaran tersebut diujicobakan dikelas kecil terlebih dahulu kemudia diuji cobakan pada kelas besar. Kelas besar terdiri dari kelas Eksperiment dan kelas Kontrol. Pemilihan kelas eksperiment dan kelas kontrol dipilih secara random kemudian diberikan pre test untuk mengetahui kemampuan awal peserta didik yang bias menunjukkan tidak ada perbedaan signifikan anatara kelas eksperiment dan kelas control. Kemudian tahap terakhir yaitu tahap penyebaran, media pembelajaran M-Learning berbasis Articulate Storyline dikemas dalam google drive dan dilaukan penyebaran menggunakan internet dan sosialisasi produk media media pembelajaran M-Learning berbasis Articulate Storyline pada MGMP Pendidikan Ekonomi di kota Probolinggo. Analisis data yang digunakan dalam penelitian ini yaitu analisis data responden menggunakan angket dengan jumlah responden 100 responden dari kelas eksperiment dan 100 responden dari kelan control, dimana responden berasal dari 4 sekolah negeri di kota Probolinggo. Analisis data selanjutnya yaitu uji normalitas, uji homogenitas, analisis 
2384 Pengembangan Media M-Learning Berbasis Aplikasi Articulate Storyline untuk Meningkatkan Hasil Belajar Peserta Didik Sekolah Menengah Atas - Ana Dwi Octavia, Jun Surjanti, Bambang Suratman DOI: https://doi.org/10.31004/edukatif.v3i5.797

data test (n-gain) dan uji test menggunakan uji paired sampel t test dengan bantuan software SPSS 20.00 for windows.

\section{HASIL DAN PEMBAHASAN PENELITIAN}

Temuan penelitian akan dibahas melalui tahapan penellitian yang dimulai dari tahapan Pendefinisian (Define). Kegiatan yang dilakukan yaitu analisis awal, analisis peserta didik, analisis konsep, analisis tugas dan analisis tujuan pembelajaran. Pada analisis awal ditemukan bahwa pembelajaran selama ini di 4 sekolah negeri masih menggunakan media konvensional berupa ppt dan media social seperti WA dalam pembelajaran sehingga peserta didik mengalami kejenuhan sehingga berdampak pada hasil pembelajaran semester pertama tidak sesuai dengan yang diharapkan. Kegiatan selanjutya yaitu kegiatan analisis peserta didik, dengan ditemukan beberapa temuan yaitu antusiasnya peserta didik dalam menggunakan smartphone tetapi pengapikasian pembelajaran belum sepenuhnya dilakukan dengan media M-Learning, kemampuan finansial peserta didik apabila menggunakan media pembelajaran yang menggunakan paketan data terlalu banyak masih belum menjangkau seperti untuk browsing materi, video dan latihan soal, kesulita peserta didik dalam memahami materi pendapatan nasional yang berupa materi hafalan dan materi hitungan.

Kegiatan selanjutnya yaitu analisis tugas dengan cara memberikan pre test untuk mengetahui tingkat pengetahuan peserta didik. Kegiatan selanjutnya analisis konsep dan perumusan tujuan pembelajaran yang disesuikan dengan berdasarkan kompetensi inti dan kompetensi dasar dalam silabus pembelajaran ekonomi kelas XI Sekolah Menengah atas.

Adapun analisis konsep dan analisis Tujuan.

\section{Tabel 1}

Analisis Konsep dan Analisis Tujuan

\begin{tabular}{|c|c|c|}
\hline Kompetensi dasar & Indikator Pencapaian Kompetensi & Tujuan pembelajaran \\
\hline $\begin{array}{l}\text { 3.1. Menganalisis } \\
\text { konsep dan metode } \\
\text { penghitungan } \\
\text { pendapatan nasional }\end{array}$ & $\begin{array}{l}\text { 3.3.1 } \begin{array}{l}\text { Mendefinisikan Pengertian } \\
\text { pendapatan nasional }\end{array} \\
\text { 3.3.2 } \begin{array}{l}\text { Menentukan Manfaat pendapatan } \\
\text { nasional }\end{array} \\
\text { 3.3.3 } \begin{array}{l}\text { Menjelaskan Komponen } \\
\text { komponen pendapatan nasional }\end{array} \\
\text { 3.3.3 } \begin{array}{l}\text { Menjelaskan Metode perhitungan } \\
\text { pendapatan nasional }\end{array} \\
\text { 3.3.4 } \begin{array}{l}\text { Menganalisis Pendapatan } \\
\text { perkapita }\end{array} \\
\text { 4.3.1 } \begin{array}{l}\text { Mempresentasikan hasil } \\
\text { perhitungan pendapatan nasional }\end{array}\end{array}$ & $\begin{array}{l}\text { Dengan menggunakan media } \\
\text { pembelajaran M-Learning } \\
\text { berbasis Articulate Storyline } \\
\text { peserta didik } \\
\text { dapatmendefinisikan Pengertian } \\
\text { pendapatan nasional } \\
\text { 1. Menentukan manfaat } \\
\text { pendapatan nasional } \\
\text { 2. Menjelaskan Komponen } \\
\text { komponen pendapatan } \\
\text { nasional } \\
\text { 3. } \begin{array}{l}\text { Menjelaskan Metode } \\
\text { perhitungan pendapatan }\end{array} \\
\text { nasional } \\
\text { 4. Menganalisis Pendapatan } \\
\text { perkapita } \\
\text { 5. Mempresentasikan hasil } \\
\text { perhitungan pendapatan } \\
\text { nasional }\end{array}$ \\
\hline
\end{tabular}

Sumber : Dikelola Peneliti (2021)

Tahap selanjutnya setelah tahapan Pendefinisian (Define) yaitu tahap perancangan (Design). Pada tahap design ini yaitu dengan pemilihan media pembelajaran yang akan digunakan yaitu media M-Learning Berbasis Articulate Storyline. Kemudian proses perancangan awal merancang media pembelajaran yang dikemas dalam bentuk animasi, video dan Latihan soal. Berikut perncangan awal media pembelajaran yang ditampilakan pada sebuah bagan. 
2385 Pengembangan Media M-Learning Berbasis Aplikasi Articulate Storyline untuk Meningkatkan Hasil Belajar Peserta Didik Sekolah Menengah Atas - Ana Dwi Octavia, Jun Surjanti, Bambang Suratman DOI: https://doi.org/10.31004/edukatif.v3i5.797

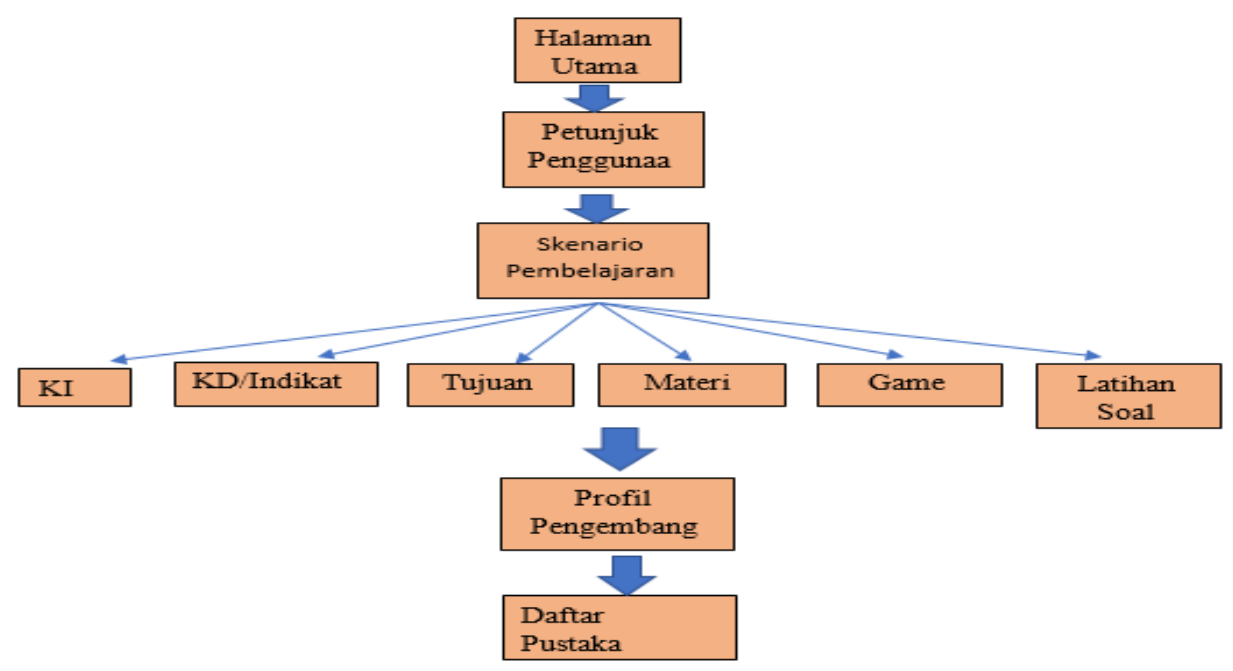

\section{Gambar 1. Perancangan awal Media M-learning Berbasis Articulate Storyline}

Tahapan selanjutnya yaitu tahap pengembangan, tahapan pengembangan bertujuan untuk mengembangkan media pembelajaran M-Learning berbasis Articulate Storyline yang dimulai dari pembuatan story board. Berikut beberapa tampilan awal dalam media pembelajaran M-Learning berbasis Articulate Storyline

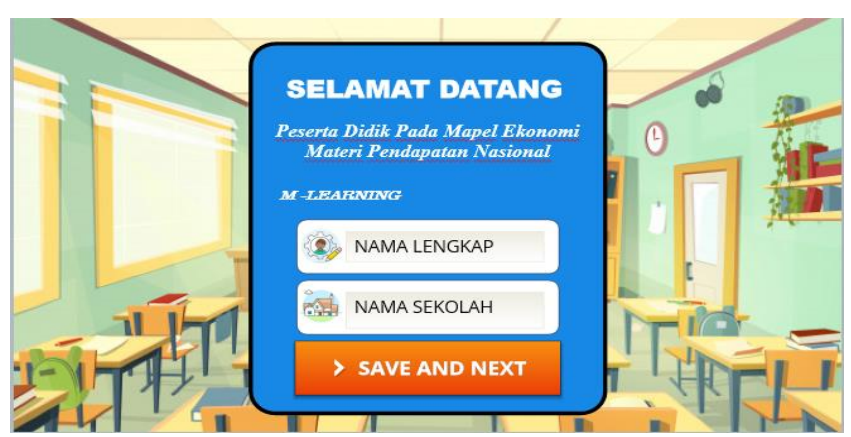

Gambar 2. Tampilan awal media pembelajaran M-Learning berbasis Articulate Storyline

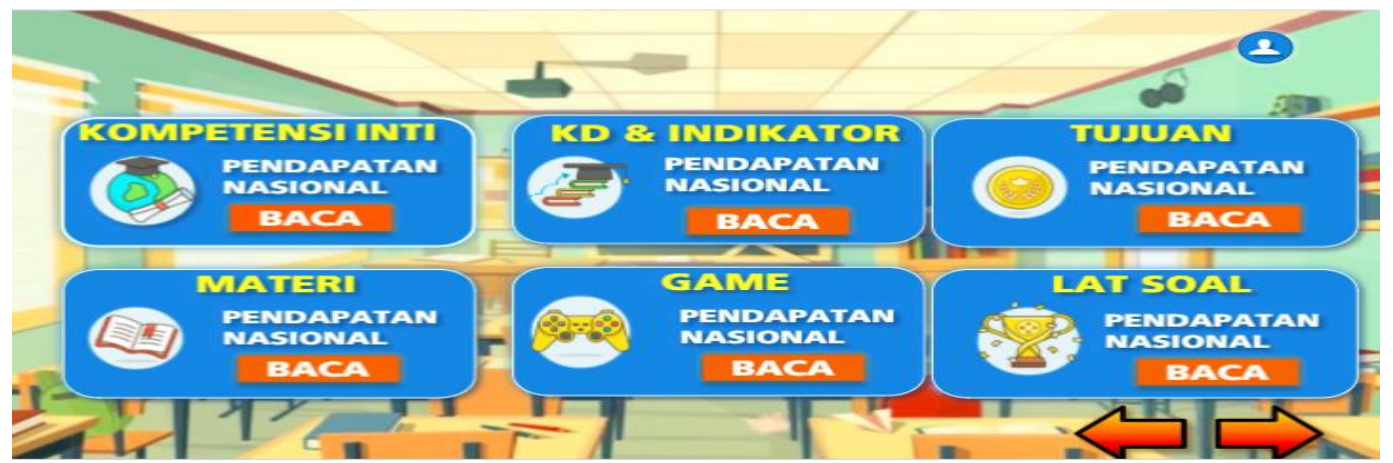

Gambar 3. Tampilan Menu media pembelajaran M-Learning berbasis Articulate Storyline 


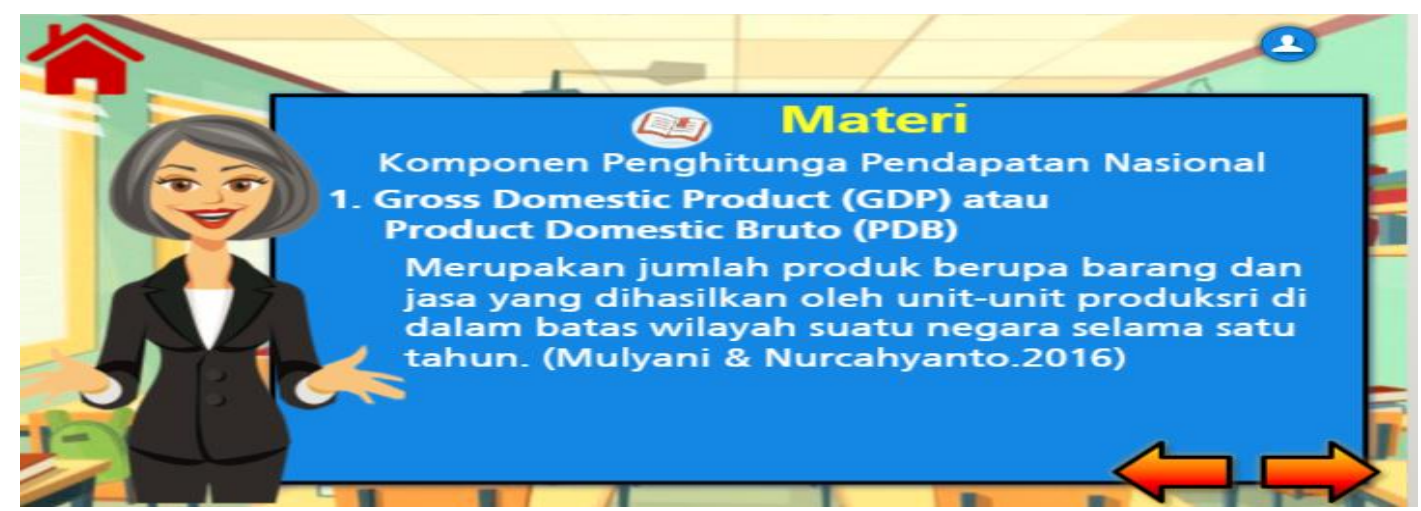

Gambar 4 Tampilan materi media pembelajaran M-Learning berbasis Articulate Storyline

Kegiatan pengembangan dimulai dengan validasi oleh ahli materi, ahli bahasa dan ahli media. Validasi yang dilakukan oleh ahli materi yang diperoleh hasil 84,6\%. Dari hasil tersebut Hal tersebut menyatakan bahawa media M-Learning Berbasis Articulate Storyline pada pembelajaran ekonomi materi pendapatan nasional yaitu sangat valid oleh ahli materi. Selain penilaian validasi materi, validator juga memberikan saran dan masukan yaitu warna kuramg kontras antara tulisan denga background, ada hasil hitungan yang slaah dalam contoh soal. Semua saran kemudian ditindak lanjuti agar menghasilkan media pembelajaran yang layak dari segi materi. Validasi selanjutnya yaitu validasi media pembelajaran yang dilakukan oleh ahli media yang diperoleh hasil 96,6 \%. Dari hasil tersebut tersebut dapat dinyatakan bahwa media M-Learning Berbasis Articulate Storyline pada pembelajaran ekonomi materi pendapatan nasional yaitu sangat valid oleh ahli media. Selain penilaian validasi ahli, validator juga memberikan saran dan masukan yaitu ketepatan tombol navigasi diperbaiki kembali kemudian backsoundnya dikurangi volumenya agar peserta didik tidak terganggung dengan backsound dalam memahami materi pada media pembelajaran. Semua saran kemudian ditindak lanjuti agar menghasilkan media pembelajaran yang layak dari segi media. Validasi selanjutnya yaitu validasi yang dilakukan pada tata bahasa yang digunakan dalam media pembelajaran M-Learning Berbasis Articulate Storyline yang diperoleh hasil $75 \%$. Dari hasil tersebut dapat dinyatakan bahwa media $M$-Learning Berbasis Articulate Storyline pada pembelajaran ekonomi materi pendapatan nasional yaitu sangat valid oleh ahli bahasa.

Setelah semua saran dari para ahli validasi ditindak lanjuti maka tahapan selanjutnya yaitu uji coba ke kelompok kecil terlebih dahulu. Kemudian dianalisis data responden yaitu peserta didik sendiri. Instrument yang digunakan dalam penelitian ini menggunakan angket dalam bentuk skala likert. Hasil analysis data responden pada uji coba kelompok kecil memperoleh skor 97,18\%kemudian diuji cobakan pada kelompok luas dengan memperoleh hasil skor sebesar 86,09\% sehingga dapat disimpulkan bahwa pembelajaran menggunakan media pembelajaran M-learning berbasis Articulate Storyline pembelajaran memperoleh respon sangat baik dari peserta didik.

Selanjutnya dilakukan uji normalitas menggunakan spss 20 yang bertujuan untuk mengetahui sebaran data normal atau tidak dari pre test dan post test dari kelas eksperiment dan kelas kontrol. Pada uji test of normality akan dikatakan normal apabila nilai signifikasi lebih dari 0,05 . Pengujian normalitas menggunakan metode Kolmogorov-Smirnov. Berikut disajikan hasil uji normalitas 
2387 Pengembangan Media M-Learning Berbasis Aplikasi Articulate Storyline untuk Meningkatkan Hasil Belajar Peserta Didik Sekolah Menengah Atas - Ana Dwi Octavia, Jun Surjanti, Bambang Suratman DOI: https://doi.org/10.31004/edukatif.v3i5.797

Tabel 2

Hasil uji Normalitas Pre dan Post Test Kelompok Eksperiment dan Kelompok Kontrol

\begin{tabular}{|c|c|c|c|c|c|}
\hline \multicolumn{6}{|c|}{ One-Sample Kolmogorov-Smirnov Test } \\
\hline & & $\begin{array}{c}\text { Hasil nila Pre } \\
\text { pada } \\
\text { kelompok } \\
\text { Eksperiment }\end{array}$ & $\begin{array}{c}\text { Hasil nila } \\
\text { Post pada } \\
\text { kelompok } \\
\text { Eksperiment }\end{array}$ & $\begin{array}{c}\text { Hasil nila Pre } \\
\text { pada } \\
\text { kelompok } \\
\text { Kontrol }\end{array}$ & $\begin{array}{l}\text { Hasil nila } \\
\text { Post pada } \\
\text { kelompok } \\
\text { Kontrol }\end{array}$ \\
\hline $\mathrm{N}$ & & 100 & 100 & 100 & 100 \\
\hline \multirow[t]{2}{*}{ Normal Parameters ${ }^{a, b}$} & Mean & 58.8700 & 85.5200 & 61.9600 & 79.8900 \\
\hline & Std. Deviation & 11.79938 & 10.14290 & 12.58420 & 11.44764 \\
\hline \multirow[t]{3}{*}{ Most Extreme Differences } & Absolute & .118 & .133 & .129 & .115 \\
\hline & Positive & .076 & .120 & .111 & .115 \\
\hline & Negative & -.118 & -.133 & -.129 & -.091 \\
\hline Kolmogorov-Smirnov Z & & 1.183 & 1.333 & 1.286 & 1.154 \\
\hline Asymp. Sig. (2-tailed) & & .122 & .057 & .073 & .140 \\
\hline
\end{tabular}

Sumber : Dikelola Peneliti (2021)

Uji normalitas pre test pada kelompok eksperiment bernilai 0,122 dan post test pada kelompok eksperiment bernilai 0,57. Kemudian uji normalitas pre test kelompok control bernilai 0,73 dan post test kelompok control bernilai 0,140. Berdasarkan hasil pengujian Kolmogorov-Smirnov, didapatkan signifikansi yang bernilai lebih besar daripada $\alpha=0,05$ pada seluruh variabel yang diamati. Oleh karena itu nilai signifikansi lebih besar daripada $\alpha=0,05$ maka disimpulkan bahwa asumsi normalitas data telah terpenuhi.

Analisis data selanjutnya dilakukan dengan Uji homogenitas ragam dilakukan untuk menguji kesamaan ragam pada nilai pembelajaran pre dan post pada metode eksperimen dan kontrol di mana tiap metode pada pengujian heterogenitas yang digunakan adalah uji Levene. Dasar pengambilan keputusan adalah dengan menggunakan signifikansi, yaitu jika signifikansi lebih besar dari alpha 5\%, maka parameter yang diamati memiliki ragam yang sama antar perlakuan (Pre atau Post) pada metode Eksperiment dan Kontrol . Hasil pengujian disajikan sebagai berikut :

Tabel 3

Hasil Uji Homogenitas

Test of Homogeneity of Variances

\begin{tabular}{|l|c|r|r|r|}
\hline & \multicolumn{1}{|c|}{$\begin{array}{l}\text { Levene } \\
\text { Statistic }\end{array}$} & df1 & \multicolumn{1}{c|}{ df2 } & \multicolumn{1}{c|}{ Sig. } \\
\hline $\begin{array}{l}\text { Hasil Nilai Pada } \\
\begin{array}{l}\text { Eksperiment } \\
\text { Hasil Nilai Pada Kontrol }\end{array}\end{array}$ & 3.592 & 1 & 198 & .060 \\
\hline
\end{tabular}

Sumber : Dikelola Peneliti (2021)

Berdasarkan table 2 dapat diketahui bahwa data hasil pembelajaran kelas eksperiment dan kelas kontrol pada nilai pre dan post memiliki signifikansi lebih besar dari alpha $5 \%(0,05)$ sehingga dapat dikatakan bahwa ragam data homogeny artinya ragam data pembelajaran kelas eksperiment dan kontrol pada pre dan post sama.

Analsis data selanjutnya diperoleh dengan analisis data test dari hasil pretest dan post test kedua sampel kelompok kelas kontrol dan kelompok kelas eksperiment yang telah diberi perlakuan, maka dilanjutkan dengan menganalisis data dan menghitung data pencapaian (gain). Hasil belajar peserta didik meningkat apabila $N$-Gain $>0,3$. Dari kelas eksperiment diperoleh n gain rata rata sebesar 0,64 yang artinya pembelajaran menggunakan kelas eksperiment setelah mendapatakan media pembelajaran M-Learning berbasis Articulate Storyline mengalami peningkatan dengan kriteria sedang. Peningkatan kriteria sedang tersebut dikarenakan penelitian ini dilakukan di 4 sekolah negeri yaitu SMAN 1, SMAN 2, SMAN 3 dan SMAN 4 yang terdiri dari 
2388 Pengembangan Media M-Learning Berbasis Aplikasi Articulate Storyline untuk Meningkatkan Hasil Belajar Peserta Didik Sekolah Menengah Atas - Ana Dwi Octavia, Jun Surjanti, Bambang Suratman DOI: https://doi.org/10.31004/edukatif.v3i5.797

beragam kemampuan peserta didik.

Kemudian N gain dari kelas Kontrol diperoleh 0,49, hasil tersebut dikategorikan sedang. Perbandingan $\mathrm{N}$ gain dari kelas Eksperiment lebih besar daripada kelas Kontrol yang tidak mendapatkan media pembelajaran M-Learning berbasis Articulate Storyline. Disini sudah jelas bahwa dengan adanya media pembelajaran yang inovatif akan memberikan hasil pencapaian belajar yang maksimal. Hal tersebut juga dikemukan bahwa pemanfaatan M-Learning akan dapat meningkatkan efktifitas pembelajaran dengan memberikan kemudahan dalam belajar, memperjelas pembelajaran menumbuhkan pembelajaran mandiri dan mengatasi kesulitan peserta didik (Surjanti et al., 2018).

Analisis data selanjutnya yaitu analisis uji $\mathrm{T}$ test dilakukan untuk mengetahui perbedaan rata rata hasil test sebelum dan sesudah adanya media pembelajaran M-learning berbasis Articulate Storyline dan untuk mengatahui juga perbedaan rata rata antara kelas eksperiment yang mendapatkan media pembelajaran Mlearning maupun kelas control yang tidak mendapatkan media pembelajaran M-learning. Kelas control pembelajarannya menggunakan pembejaran secara konvesional saja. Uji ini menggunakan uji paired sampel t test dengan dasar pengambilan keputusan jika diperoleh signifikasi $<0,05$ menunjukan adanya perbedaan yang signifikan anatar hasil belajar setelah menggunakan media M-Learning Berbasis Articulate Storyline, tetapi jika memperoleh signifikasi . 0,05 menunjukan tidak adanya perubahan yang signifikan antara hasil bejar setelah menggunakan media M-Learning berbasis Articulate Storyline. Berikut analisis data kelas eksperiment sebelum dan sesudah mendapatkan media pembejaran Articulate Storyline

Tabel 4

Perbandingan Nilai pembelajaran Kelas Eksperiment sebelum dan sesudah

\begin{tabular}{crrrrr}
\hline $\begin{array}{c}\text { Pembelajaran Kelas } \\
\text { Eksperiment }\end{array}$ & Rata-rata & $\begin{array}{c}\text { Standar } \\
\text { Error }\end{array}$ & Standar Deviasi & t & Signifikansi \\
\hline Sebelum & 58,87 & 1,179 & 11,799 & $-19,909$ & 0 \\
\hline Sesudah & 85,52 & 1,014 & 10,142 & 000 \\
\hline
\end{tabular}

Pada pembelajaran sebelum Metode Eksperiment diperoleh rata-rata sebesar 58,87 \pm 11,799 dari 100 siswa. Sedangkan pembelajaran sesudah metode Eksperiment diperoleh rata-rata sebesar 85,52 $\pm 10,142$ dari 100 siswa. Berdasarkan tabel 4.4 diperoleh nilai t sebesar $|19,909|$ dan nilai signifikansi sebesar 0,000 , di mana nilai signifikansi tersebut kurang dari $0,05(0,000<0,050)$. Pembelajaran pada kelas Eksperiment sebelum dan sesudah memiliki perbedaaan yang signifikan. Sehingga diperoleh kesimpulan bahwa kelas Eksperiment memiliki nilai rata rata yang lebih tinggi dari pada sebelum media pembejaran M-Learning berbasis Articulate Storyline diterapkan.

Tabel 5

Perbandingan Nilai pembelajaran Kelas Kontrol sebelum dan sesudah

\begin{tabular}{|c|c|c|c|c|c|}
\hline Pembelajaran Kontrol & Rata-rata & Standar Error & Standar Deviasi & $\mathbf{t}$ & Signifikansi \\
\hline Sebelum & 61,96 & 1,258 & 12,58 & \multirow[b]{2}{*}{$-21,148$} & \multirow[b]{2}{*}{0,000} \\
\hline Sesudah & 79,89 & 1,144 & 11,44 & & \\
\hline
\end{tabular}

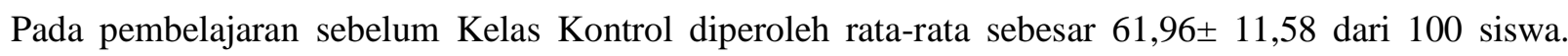
Sedangkan pembelajaran sesudah Kelas Kontrol, diperoleh rata-rata sebesar 79,89 $\pm 11,44$ dari 100 siswa. Berdasarkan tabel 4 diperoleh nilai t sebesar $|21,148|$ dan nilai signifikansi sebesar 0,000 , di mana nilai signifikansi tersebut kurang dari $0,05(0,000<0,050)$. Kemudian akan dibandingkan antara kelas control dengan kelas eksperiment . berikut disajikan perbandingan kelas control dengan kelas eksperiment 
2389 Pengembangan Media M-Learning Berbasis Aplikasi Articulate Storyline untuk Meningkatkan Hasil Belajar Peserta Didik Sekolah Menengah Atas - Ana Dwi Octavia, Jun Surjanti, Bambang Suratman DOI: https://doi.org/10.31004/edukatif.v3i5.797

Tabel 6

Perbandingan kelas Eksperiment dan kelas Kontrol

\begin{tabular}{|c|c|c|c|c|c|}
\hline \multicolumn{6}{|c|}{ Paired Samples Statistics } \\
\hline & & Mean & $\mathrm{N}$ & Std. Deviation & $\begin{array}{l}\text { Std. Error } \\
\text { Mean }\end{array}$ \\
\hline \multirow[t]{2}{*}{ Pair 1} & $\begin{array}{l}\text { Hasil nila Pre pada } \\
\text { kelompok Eksperiment }\end{array}$ & 58.8700 & 100 & 11.79938 & 1.17994 \\
\hline & $\begin{array}{l}\text { Hasil nila Post pada } \\
\text { kelompok Eksperiment }\end{array}$ & 85.5200 & 100 & 10.14290 & 1.01429 \\
\hline \multirow[t]{2}{*}{ Pair 2} & $\begin{array}{l}\text { Hasil nila Pre pada } \\
\text { kelompok Kontrol }\end{array}$ & 61.9600 & 100 & 12.58420 & 1.25842 \\
\hline & $\begin{array}{l}\text { Hasil nila Post pada } \\
\text { kelompok Kontrol }\end{array}$ & 79.8900 & 100 & 11.44764 & 1.14476 \\
\hline
\end{tabular}

Pada kelas ekperiment yang menggunakan media pembelajaran M-Learning berbasis Articulate Storyline terdapat peningkatan nilainya lebih besar jika dibandingkan dengan kelas kontrol yang hanya menggunakan media pembelajaran secara konvensional. Rata-rata nilai post test pada kelas Eksperiment 85,52 sedangkan pada kelas control yang tidak mendapatkan media M-Learning berbasis Articulate Storyline rata rata nilai post test 79,89

Berdasarkan hasil validasi dari ahli materi, ahli media dan ahli bahasa ditemukan bahwa media $M$ Learning berbasis Articulate Storyline telah valid dan sangat layak digunakan dalam pembelajaran, materi yang disajikan sudah sesuai dengan tujuan pembelajaran yang hendak dicapai, media pembelajaran yang digunakan juga inovatif dengan perkembangan teknologi. Temuan dalam penelitian ini diperkuat dengan penyataan Budiono (2014) yang menyatakan bahwa kualitas animasi, video, grafik dan game mendapatkan skor rata-rata 4. Selain susunan kalimat yang digunakan juga mudah dipahami oleh peserta didik. Hal ini selaras dengan pernyataan bahwa media pembelajaran Articulate Storyline memperoleh validasi yang baik dari validator sehingga dapat disimpulkan bahwa media pembelajaran menggunakan Articulate Storyline sangat layak digunakan dalam proses pembelajaran (Purnama \& Asto B, 2014). Pernyataan lain yang mendukung hasil temua dalam peneltian ini yaitu Penelitian sebelumnya yang menyatakan bahwa berdasarkan hasil validasi dari ahli media memperoleh predikat sangat baik dan respon peserta didik juga sangat baik dalam penggunaan media pembelajarn ini (Arwanda et al., 2020)

Temuan lain dalam penelitian ini yaitu dengan adanya media M-Learning berbasis Articulate Storyline lebih menyenangkan dan materi lebih mudah dipahami dengan baik. Hal ini sesuai dengan pernyataan bahwa pembelajaran menggunakan aplikasi Articulate Storyline dapat mengurangi kecemasan peserta didik sehingga tercapainya hasil belajar yang meningkat (Alioon \& Delialioğlu, 2019). Peneltian sebelumnya juga memperkuat bahwa hasim pemahaman materi dalam media articulate Storyline ini sangat mudah dipahami sehuingga dapat dikatakan sangat layak penggunaan media Articulte Storyline dalam pembelajara (. \& ., 2015). Selain itu terdapat temuan dalam penelitian ini yaitu adanya peningkatan capain hasil belajar yang diyatakan dengan $\mathrm{N}$ gain terdapat peningkatan sedang sebesar 0,64 pada kelas eksperiment dan 0,49 pada kelas kontrol. Sehingga dapat dinyatakan penggunaan media M-Learning berbasis Articulate Storyline terdapat peningkatan hasil belajar sesuai dengan yang diharapkan. Jadi penggunaan media pembelajaran yang inovatif yang selaras dengan perkembangan teknologi akan dapat tercapainya hasil belajar yang memuaskan. Hal ini selaras dengan pernyataan bahwa tercapainya hasil belajar diatas rata rata yaitu diata 75 dengan menggunakan media pembelajaran Articulate Storyline (Pratama, 2019).

\section{KESIMPULAN}

Berdasarkan temuan penelitian dinyatakan bahwa pengembangan media pembelajaran M-Learning berbasis Articulate Storyline untuk meningkatkan hasil belajar peserta didik SMA Negeri telah dinyatakan 
2390 Pengembangan Media M-Learning Berbasis Aplikasi Articulate Storyline untuk Meningkatkan Hasil Belajar Peserta Didik Sekolah Menengah Atas - Ana Dwi Octavia, Jun Surjanti, Bambang Suratman DOI: https://doi.org/10.31004/edukatif.v3i5.797

valid, praktis dan signifikan. Penelitian ini membuktikan bahwa penggunaan media pembelajaran yang menggunakan teknologi akan memberikan hasil yang signifikan terhadap hasil belajar peserta didik. Saran penelti yaitu agar pendidik harus bisa berinovasi dalam menggunakan media pembelajaran agar tercipta hasil belajar yang baik dan menyenagkan. Implikasi dari penelitian ini dapat dijadikan sebagai referensi praktisi pendidikan untuk meningkatkan hasil belajar peserta didik.

\section{UCAPAN TERIMA KASIH}

Ucapan terimakasih kepada Universitas Negeri Surabaya karena telah memberikan ijin terhadap pelaksanaan penelitian ini.

\section{DAFTAR PUSTAKA}

S., \& . L. (2015). Pengembangan Media Pembelajaran Interaktif Berbasis Articulate Storyline Pada Mata Diklat Teknik Elektronika Dasar Di Smk Negeri 1 Jetis Mojokerto. Jurnal Pendidikan Teknik Elektro, 4(3), 845-849.

Alioon, Y., \& Delialioğlu, Ö. (2019). The effect of authentic m-learning activities on student engagement and motivation. In British Journal of Educational Technology (Vol. 50, Issue 2, pp. 655-668). https://doi.org/10.1111/bjet.12559

Arwanda, P., Irianto, S., \& Andriani, A. (2020). Pengembangan Media Pembelajaran Articulate Storyline Kurikulum 2013 Berbasis Kompetensi Peserta Didik Abad 21 Tema 7 Kelas Iv Sekolah Dasar. Jurnal Ilmiah Pendidikan Madrasah Ibtidaiyah, 4(2), 193-204. https://doi.org/10.35931/am.v4i2.331

Asmari, A. Al. (2016). Continuous Professional Development of English Language Teachers: Perception and Practices. Advances in Language and Literary Studies, 7(3). https://doi.org/10.7575/aiac.alls.v.7n.3p.117

Budiono, J. D. (2014). BioEdu BioEdu. 3(3), 571-579.

Dasar, J. P. (2016). Efektifitas Media Animasi Dalam Pencapaian Nilai Kriteria Ketuntasan Minimal. Jurnal Pesona Dasar, 2(4), 1-7. https://doi.org/10.24815/pear.v7i2.14753

Destyana, V. A., \& Surjanti, J. (2021). EDUKATIF : JURNAL ILMU PENDIDIKAN Efektivitas Penggunaan Google Classroom dan Motivasi Belajar Terhadap Hasil Belajar Peserta Didik Mata Pelajaran Ekonomi. 3(3), 1000-1009.

Effendi, H., \& Hendriyani, Y. (2018). Mobile Learning sebagai Alternatif Pengembangan Keprofesian Berkelanjutan Guru Profesional. https://doi.org/10.31227/osf.io/v83ef

Martono Kurniawan, T., \& Nurhayati Oky, D. (2014). Implementation of Android-Based Mobile Learning Application as a Flexible Learning Media. International Journal of Computer Science Issues, 11(3), $168-174$.

Munirah, M. (2018). Peranan Guru dalam Mengatasi Kesulitan Belajar Siswa. TARBAWI : Jurnal Pendidikan Agama Islam, 3(02), 111-127. https://doi.org/10.26618/jtw.v3i02.1597

Nafrin, I. A., \& Hudaidah, H. (2021). Perkembangan Pendidikan Indonesia di Masa Pandemi Covid-19. Edukatif: Jurnal Ilmu Pendidikan, 3(2), 456-462. https://doi.org/10.31004/edukatif.v3i2.324

Novaliendry, D., Darmi, R., Hendriyani, Y., Nor, M., \& Azman, A. (2020). Smart Learning Media Based on Android Technology. International Journal of Innovation, Creativity and Change., 12(11), 715-735.

Pranaja, A., \& Astuti, Y. (2019). Edukatif: Jurnal Ilmu Pendidikan. Jurnal Ilmu Pendidikan, 1(3), 294-302. https://edukatif.org/index.php/edukatif/index

Pratama, R. A. (2019). Media Pembelajaran Berbasis Articulate Storyline 2 Pada Materi Menggambar Grafik Fungsi Di Smp Patra Dharma 2 Balikpapan. Jurnal Dimensi, 7(1), 19-35.

https://doi.org/10.33373/dms.v7i1.1631 
2391 Pengembangan Media M-Learning Berbasis Aplikasi Articulate Storyline untuk Meningkatkan Hasil Belajar Peserta Didik Sekolah Menengah Atas - Ana Dwi Octavia, Jun Surjanti, Bambang Suratman DOI: https://doi.org/10.31004/edukatif.v3i5.797

Purnama, S., \& Asto B, I. G. P. (2014). Pengembangan Media Pembelajaran Interaktif Menggunakan Software Articulate Storyline Pada Mata Pelajaran Teknik Elektronika Dasar Kelas X TEI 1 Di SMK Negeri 2 Probolinggo. Jurnal Pendidikan Teknik Elektro, 3(2), 275-279.

Suriadi, H. J., Firman, F., \& Ahmad, R. (2021). Analisis Problema Pembelajaran Daring Terhadap Pendidikan Karakter Peserta Didik. Edukatif: Jurnal Ilmu Pendidikan, 3(1), 165-173. https://doi.org/10.31004/edukatif.v3i1.251

Surjanti, J., Seno, D. N., Hadi, H. K., Maroah, S., Siswanti, Y., Muafi, \& Isfianadewi, D. (2018). The role of M-learning on effective learning media in higher education. International Journal of Civil Engineering and Technology, 9(4), 77-85.

Undang-undang Republik Indonesia No 14 Tahun 2005 tentang Guru dan Dosen.

Wahyuningtyas, R., \& Sulasmono, B. S. (2020). Pentingnya Media dalam Pembelajaran Guna Meningkatkan Hasil Belajar di Sekolah Dasar. Edukatif: Jurnal Ilmu Pendidikan, 2(1), 23-27. https://doi.org/10.31004/edukatif.v2i1.77

Yunitasari, R., \& Hanifah, U. (2020). Pengaruh Pembelajaran Daring Terhadap Minat Belajar Siswa Pada Masa COVID 19. Edukatif: Jurnal Ilmu Pendidikan, 2(3), 232-243.

https://Doi.Org/10.31004/Edukatif.v2i3.142 